\title{
Effect of sensor systems for cow management on milk production, somatic cell count, and reproduction
}

\author{
W. Steeneveld, ${ }^{* 1}$ J. C. M. Vernooij, $†$ and H. Hogeveen ${ }^{*} \dagger$ \\ ${ }^{*}$ Chair group Business Economics, Wageningen University, Hollandseweg 1, $6706 \mathrm{KN}$ Wageningen, the Netherlands \\ †Department of Farm Animal Health, Faculty of Veterinary Medicine, Utrecht University, Yalelaan 7, 3584 CL Utrecht, the Netherlands
}

\begin{abstract}
To improve management on dairy herds, sensor systems have been developed that can measure physiological, behavioral, and production indicators on individual cows. It is not known whether using sensor systems also improves measures of health and production in dairy herds. The objective of this study was to investigate the effect of using sensor systems on measures of health and production in dairy herds. Data of 414 Dutch dairy farms with $(\mathrm{n}=152)$ and without $(\mathrm{n}=262)$ sensor systems were available. For these herds, information on milk production per cow, days to first service, first calving age, and somatic cell count (SCC) was provided for the years 2003 to 2013. Moreover, year of investment in sensor systems was available. For every farm year, we determined whether that year was before or after the year of investment in sensor systems on farms with an automatic milking system (AMS) or a conventional milking system (CMS), or whether it was a year on a farm that never invested in sensor systems. Separate statistical analyses were performed to determine the effect of sensor systems for mastitis detection (color, SCC, electrical conductivity, and lactate dehydrogenase sensors), estrus detection for dairy cows, estrus detection for young stock, and other sensor systems (weighing platform, rumination time sensor, fat and protein sensor, temperature sensor, milk temperature sensor, urea sensor, $\beta$-hydroxybutyrate sensor, and other sensor systems). The AMS farms had a higher average SCC (by 12,000 cells/mL) after sensor investment, and CMS farms with a mastitis detection system had a lower average SCC (by 10,000 cells $/ \mathrm{mL}$ ) in the years after sensor investment. Having sensor systems was associated with a higher average production per cow on AMS farms, and with a lower average production per cow on CMS farms in the years after investment. The
\end{abstract}

Received November 13, 2014.

Accepted March 10, 2015

${ }^{1}$ Corresponding author: wilma.steeneveld@wur.nl most likely reason for this lower milk production after investment was that on $96 \%$ of CMS farms, the sensor system investment occurred together with another major change at the farm, such as a new barn or a new milking system. Most likely, these other changes had led to a decrease in milk production that could not be compensated for by the use of sensor systems. Having estrus detection sensor systems did not improve reproduction performance. Labor reduction was an important reason for investing in sensor systems. Therefore, economic benefits from investments in sensor systems can be expected more from the reduction in labor costs than from improvements in measures of health and production in dairy herds.

Key words: dairy, sensor, milk production, somatic cell count

\section{INTRODUCTION}

A sensor system is defined as a device that measures a physiological or behavioral parameter of an individual cow and enables automated, on-farm detection of changes in the condition that is related to a health event and requires action on the part of the farmer (Rutten et al., 2013). Sensor systems are beginning to be used on dairy farms on a larger scale. For instance, activity meters are used to detect estrus (e.g., Firk et al., 2002; O'Connell et al., 2010; Holman et al., 2011) and lameness (Pastell et al., 2009; Chapinal et al., 2010; Miekley et al., 2012). More recently, sensors that measure rumination time (Büchel and Sundrum, 2014) and the weight of cows (van der Tol and van der Kamp, 2010) have been introduced to gain insight into the health of cows. On farms with an automatic milking system (AMS), sensors have been used to detect mastitis, whereas on farms with a conventional milking system (CMS), sensors are much less likely to be used to detect mastitis. A weighing platform and sensor systems to determine the fat and protein contents in milk are used more frequently on farms with an AMS than on farms with a CMS. The use of sensor systems thus differs for farms using different milking systems (Steeneveld and Hogeveen, 2015). 
Reasons for investing in sensor systems vary. Some farmers use a sensor because it was standard equipment in the AMS, but other farmers have deliberately invested in sensors to improve detection of estrus and diseases or to gain insight into the health and fertility of their herds (Steeneveld and Hogeveen, 2015). Several studies indicate that estrus detection performance can be improved by the use of sensor systems. Sensor systems can detect approximately 80 to $85 \%$ of cows in estrus (e.g., Hockey et al., 2010; Kamphuis et al., 2012 ), whereas visual methods detect only $55 \%$ of cows in estrus (Firk et al., 2002).

So far, research on sensor systems has focused on the development of the sensors and the detection performance (for a review, see Rutten et al., 2013). Use of sensor systems can improve estrus and disease detection. It is not known, however, whether using sensor systems also improve measures of health and production, such as average days to first service and average SCC. Therefore, it is not clear whether the use of SCC sensors improves the average SCC of the herd, and whether the use of sensor systems for estrus detection results in a lower average days to first service of the herd. Previous normative studies show that higher estrus detection resulted in a shorter calving interval (Inchaisri et al., 2010; Rutten et al., 2014), but empirical studies on this effect do not exist. Probably, the use of sensor systems increases the milk production level of the herd as well, because it is known that a shorter calving interval results in higher milk production (Auldist et al., 2007) and that a high SCC causes milk production losses (e.g., Halasa et al., 2009). Increased milk production with an AMS has been observed, and this is because an AMS can facilitate more than 2 milkings per day (Kruip et al., 2002; Wagner-Storch and Palmer, 2003; Speroni et al., 2006). It is not known whether sensor systems in an AMS result in any additional milk production above the effect of increased milking frequency.

The objective of this study was to investigate the effect of using sensor systems on measures of health and production in dairy herds (average milk production, SCC, days to first service, and age at first calving). We accounted for whether the sensor systems were on farms with an AMS or a CMS. First, analyses were performed to investigate the effect of using sensor systems for the detection of mastitis on the average SCC and milk production level of the herd. Second, analyses were conducted to investigate the effect of using sensor systems for detection of estrus on the days to first service, age at first calving, and milk production level of the herd. Finally, analyses will be carried out to investigate the effect of other sensor systems on the milk production level of the herd.

\section{MATERIALS AND METHODS}

\section{Data Collection}

A survey was conducted in the Netherlands in 2013 about the use of sensor systems on dairy farms. A link to the survey was sent by e-mail to 1,672 Dutch dairy farmers. The list with e-mail addresses was provided by a Dutch accounting agency (Accon AVM, Leeuwarden, the Netherlands). The farms were located throughout the Netherlands but the majority of farms were in the north. In total, 512 farms completed the survey (response rate of $30.6 \%$ ), 202 farms indicated that they had sensor systems, and 310 farms indicated that they did not have sensor systems. The farmers indicated which sensor systems were available on their farms using a predefined list of sensor systems (Table 1). Farms not having at least one of the sensor systems mentioned in this list were defined as farms without sensor systems. For the farms with sensor systems, information was collected on the type of sensor system, whether the sensor system was part of an AMS, and the year of investment. More information about the data collection is described by Steeneveld and Hogeveen (2015).

In total, 414 farms gave permission to use measures of health and production that CRV (Cattle Improvement Cooperative, Arnhem, the Netherlands) had about their farms; CRV provided information about yearly averages for milk production, SCC, and reproduction of those 414 farms for the years 2003 to 2013.

\section{Data Editing}

Of the 414 farms, 152 farms had at least one sensor system (year of first investment ranged between 1998 and 2013) and 262 farms did not have any sensor system. An overview of the sensor systems on the 152 farms is given in Table 1. The initial data set consisted of 4,353 farm-years, with information on measures of health and production on the farms.

For the analyses, 4 data sets were created. The data set "Mastitis" consisted of farms with sensor systems for mastitis detection (color sensors, SCC sensors, electrical conductivity sensors, and lactate dehydrogenase sensor; $\mathrm{n}=122$ ) and farms without any sensor system $(\mathrm{n}=262)$. To determine only the effect of mastitis detection sensor systems, 27 farms were excluded because they had sensor systems other than those for mastitis detection. In addition, 3 farms were excluded because they did not have complete SCC information. The year of the first investment in sensor systems for mastitis detection was excluded because the month of investment was unknown. The final data set Mastitis consisted of 3,796 farm-years. 
Table 1. Overview of sensor systems present on farms with an automatic milking system (AMS) or a conventional milking system (CMS)

\begin{tabular}{lcc}
\hline & $\begin{array}{c}\text { No. of AMS farms } \\
(\mathrm{n}=103)\end{array}$ & $\begin{array}{c}\text { No. of CMS farms } \\
(\mathrm{n}=49)\end{array}$ \\
Type of sensor system at the farm & 101 & 20 \\
\hline Electrical conductivity sensor $^{1}$ & 64 & 0 \\
Color sensor $^{1}$ & 15 & 1 \\
SCC sensor $^{1}$ & 2 & 46 \\
Lactate dehydrogenase sensor $^{1}$ & 47 & 1 \\
Activity meters or pedometers for dairy cows $^{2}$ & 1 & 3 \\
Progesterone sensor $^{2}$ & 52 & 3 \\
Milk temperature sensor $^{3}$ & 32 & 0 \\
Weighing platform $^{3}$ & 23 & 10 \\
Fat and protein sensor $^{3}$ & 11 & 9 \\
Rumination activity sensor $^{3}$ & 6 & 1 \\
Temperature sensor $^{3}$ & 2 & 4 \\
BHBA sensor $^{3}$ & 1 & 17 \\
Urea sensor $^{3}$ & 4 & \\
Other sensor systems $^{3}$ & 13 & \\
Activity meters or pedometers for young stock $^{4}$ & & \\
${ }^{1}$ Defined as sensor system for mastitis detection. & & \\
${ }^{2}$ Defined as sensor system for estrus detection for dairy cows. & & \\
${ }^{3}$ Defined as other sensor system. & & \\
${ }^{4}$ Defined as sensor system for estrus detection for young stock. & &
\end{tabular}

The data set "Estrus_Dairy" consisted of farms with sensor systems for estrus detection for dairy cows (activity meters or pedometers or a progesterone sensor; $\mathrm{n}$ $=95)$ and farms without any sensor system $(\mathrm{n}=262)$. To determine only the effect of estrus detection sensor systems, 52 farms were excluded because they had sensor systems other than those for estrus detection. In addition, 5 farms were excluded because they did not have complete reproduction information. The year of the first investment in sensor systems for estrus detection was excluded because the month of investment was unknown. The final data set Estrus_Dairy consisted of 3,694 farm-years.

The data set "Other" consisted of farms with other sensor systems (weighing platform, rumination time sensor, fat and protein sensor, temperature sensor, milk temperature sensor, urea sensor, BHBA sensor, and other sensor systems; $\mathrm{n}=69$ ) and farms without any sensor systems $(\mathrm{n}=262)$. To determine only the effect of other sensor systems, 75 farms were excluded because they had sensor systems for mastitis and estrus detection. In addition, 8 farms were excluded because they did not have complete milk production information. The year of the first investment in other sensor systems was excluded because the month of investment was unknown. The final data set Other consisted of 3,416 farm-years.

The data set "Estrus_Youngstock" consisted of farms with $(\mathrm{n}=30)$ and without $(\mathrm{n}=374)$ sensor systems for estrus detection for young stock. In total, 10 farms were excluded because they did not have complete reproduction information for youngstock. The year of invest- ment was excluded because the month of investment was unknown. The final data set Estrus_Youngstock consisted of 4,309 farm-years.

\section{Statistical Analyses}

In total, 6 statistical analyses were performed. For the first analysis, data set Mastitis was used, and the effect of having sensor systems for mastitis detection on the average yearly SCC of the herd was determined. The average yearly SCC was the dependent variable, and year, percentage growth in herd size, and whether the farm had a sensor system for mastitis detection were included as independent variables.

For the second analysis, data set Mastitis was used and the effect of having sensor systems for mastitis detection on the average yearly milk production per cow was determined. The SCC of the herd and whether the farm is milking with an AMS were taken into account in the analysis to determine whether the effect on milk production was caused by the use of sensor systems or by the SCC of the herd and milking with an AMS. Average yearly production per cow was the dependent variable, and year, percentage growth in herd size, average SCC, and whether the farm had a sensor system for mastitis detection were included as independent variables.

For the third analysis, data set Estrus_Dairy was used, and the effect of having sensor systems for estrus detection for dairy cows on the days to first service was determined. The average days to first service was the dependent variable, and year, percentage growth in 
herd size, and whether the farm had a sensor system for estrus detection for dairy cows were included as independent variables.

For the fourth analysis, Estrus_Dairy was used and the effect of having sensor systems for estrus detection on the average yearly milk production per cow was determined. Whether the farm was milking with an AMS and days to first service were taken into account in the analysis to determine whether the effect on milk production was caused by the use of sensor systems or by milking with an AMS or by the days to first service. Average yearly production per cow was the dependent variable, and year, percentage growth in herd size, days to first service, and whether the farm has a sensor system for estrus detection were included as independent variables.

For the fifth analysis, data set Other was used, and the effect of having other sensor systems on the average yearly milk production per cow was determined. Average yearly production per cow was the dependent variable, and year, percentage growth in herd size, and whether the farm had other sensor systems were included as independent variables.

For the sixth analysis, data set Estrus_Youngstock was used, and the effect of having sensor systems for estrus detection for youngstock on the average age at first calving was determined. The average age at first calving was the dependent variable, and year and whether the farm had a sensor system for estrus detection for youngstock were included as independent variables.

In all analyses, growth in herd size was defined as the percentage increase or decrease in number of cows compared with that $2 \mathrm{yr}$ earlier. Whether the farm had a sensor system (for mastitis detection, estrus detection, or other) for the years in the data set was defined as follows: 0 = years without sensor system for farms that never invested in sensor systems, $1=$ years before the investment in sensor system on AMS farms, 2 = years after the investment in sensor system on AMS farms, 3 $=$ years before the investment in sensor system on CMS farms, and $4=$ years after the investment in sensor system on CMS farms. Herd was included as a random effect. All variables were analyzed using a backward stepwise procedure. Only variables at $P \leq 0.05$ in the Wald test were retained in the model. Predicted values were calculated to compare milk production, SCC, days to first service, and age at first calving of the farms before and after investment in sensor systems. Goodness of fit of all models was assessed by judging the residuals. The residuals were plotted against the fitted values and judged for peculiarities (Dohoo et al., 2009). All data editing and all analyses were performed with PROC MIXED in SAS (version 9.3; SAS Institute Inc., Cary, NC).

\section{RESULTS}

Table 1 gives an overview of the sensor systems present on the 152 farms with sensor systems. The electrical conductivity sensor was the most used sensor for mastitis detection, especially on AMS farms. In addition, half of the AMS farms had a color sensor for mastitis detection, and the SCC sensor was only available on AMS farms. In total, 47 and 46 farms with an AMS and a CMS, respectively, had activity meters or pedometers for the detection of estrus. The sensor systems for milk temperature, fat and protein, and weighing platform were mainly present on the AMS farms, whereas the rumination activity sensor was available on both AMS and CMS farms. On both AMS and CMS farms, activity meters or pedometers for youngstock were present.

Descriptive statistics about farm years without sensor systems and farm years of AMS and CMS farms before and after investment in sensor systems are presented in Table 2. The number of dairy cows present on farms was higher in the years after investment in one or more sensor systems and, especially on CMS farms, the growth in herd size increased after investment in a sensor system. Milk production level of the herds was higher in the years after investment on AMS farms and lower in the years after investment on CMS farms. On both AMS and CMS farms, average yearly SCC was lower in the years after investment in mastitis detection sensor systems. Days to first service was lower on both AMS and CMS farms in the years after investment in estrus detection sensor systems.

The factors having a mastitis detection sensor system, year, and growth in herd size were associated with the average SCC of the herd (Table 3). The AMS farms had a higher average SCC (by 12,000 cells $/ \mathrm{mL}$ ) after the investment, and the CMS farms with a mastitis detection system had a lower average SCC (by 10,000 cells $/ \mathrm{mL}$ ) in the years after investment (Figure 1). Having a mastitis detection sensor system, year, average SCC, and growth in herd size were all associated with the milk production level of the herd (Table 3). The AMS farms with mastitis detection sensor systems had a higher average production (by $189 \mathrm{~kg}$ ) per cow after investment, whereas CMS farms with mastitis detection sensor systems had a lower average milk production per cow (by $428 \mathrm{~kg}$ ) after the investment in mastitis detection sensor systems (Figure 2).

Having an estrus detection sensor system was not associated with average days to first service of the farm but was associated with the average yearly production per cow (Table 4 and Figure 2). Only year and growth in herd size were associated with average days to first service of the farm (Table 4). 
Table 2. Descriptive statistics (means with SD in parentheses) for the years 2003 to 2013 of farms with no sensor system and for the years before and after investment in sensor systems on farms with automatic milking systems (AMS) and conventional milking systems (CMS)

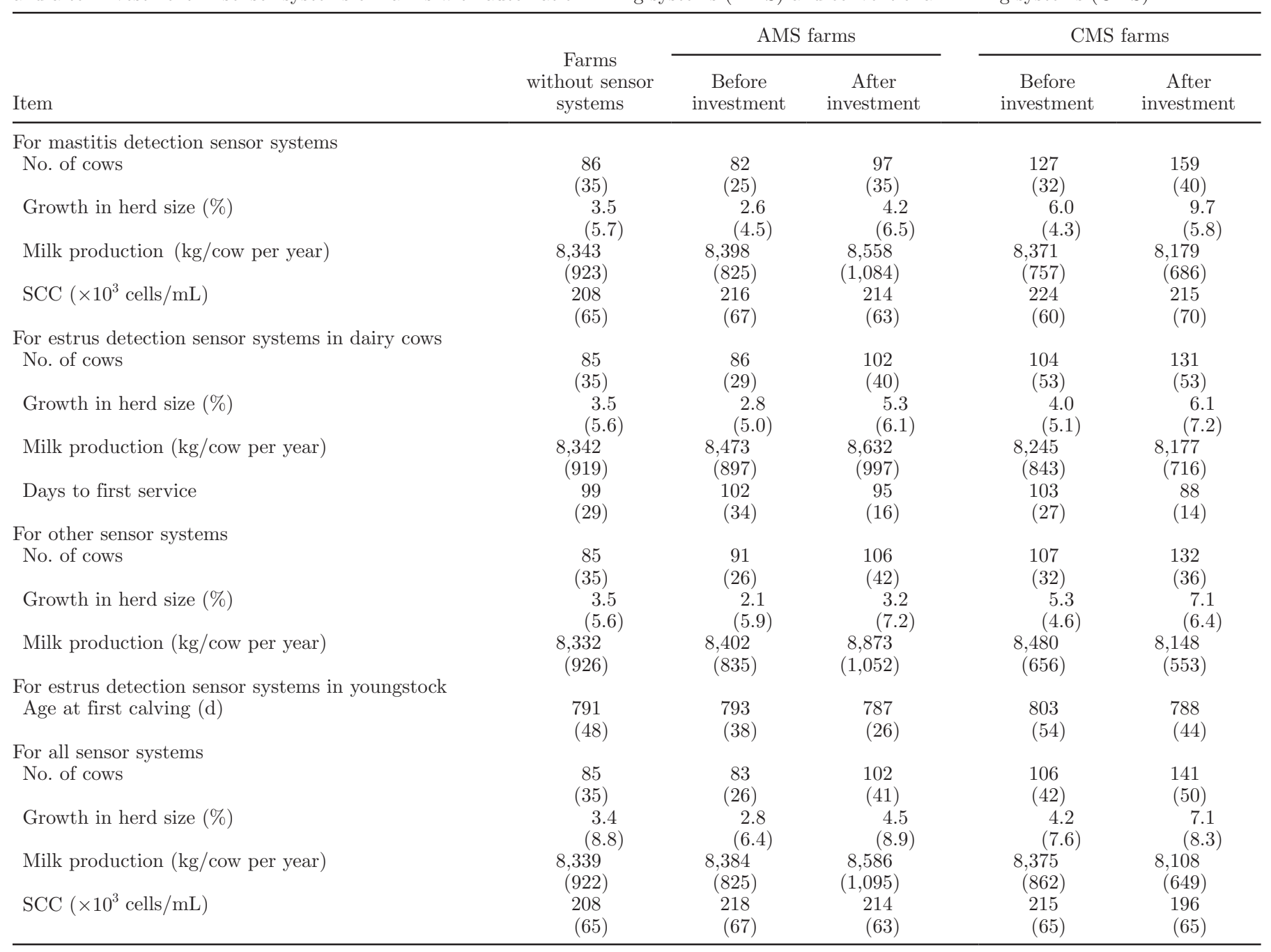

Having an estrus detection sensor system for youngstock was not associated with average age at first calving (Table 5). Having other sensors, year, and growth in herd size were significantly associated with average yearly milk production per cow (Table 5). The AMS farms with other sensor systems had a higher average production per cow (by $389 \mathrm{~kg}$ ) in the years after the investment, whereas the CMS farms with other sensor systems had a lower average milk production per cow $(299 \mathrm{~kg})$ in the years after the investment (Figure 2).

\section{DISCUSSION}

Having mastitis detection sensor systems was associated with a decreased average SCC on CMS farms and with an increased average SCC on AMS farms in the years after the investment (analysis 1). We also found that having mastitis detection, estrus detection, and other sensor systems was associated with a higher average production per cow on AMS farms, and with a lower average production per cow on CMS farms in the years after investment (analyses 2, 4, and 5). Having an estrus detection sensor system was not associated with average days to first service or average age at first calving (analyses 3 and 6). This is the first study to investigate the effect of sensor systems on measures of health and production in dairy herds; therefore, we cannot make comparisons with other studies.

Previous studies (Rasmussen et al., 2002; Dohmen et al., 2010) have investigated the effect of milking with an AMS on SCC and milk production; those researchers reported that udder health is at risk on farms with an AMS. Several studies have been published regarding the increase in bulk milk SCC after the transition from conventional to automatic milking (Rasmussen et al., 2002; Dohmen et al., 2010). We also found that farms 


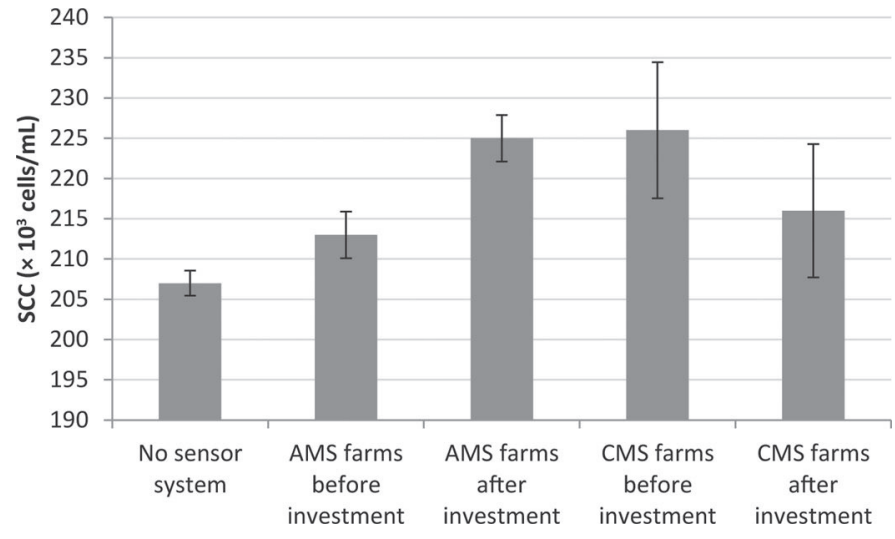

Figure 1. Estimated average SCC for farms with no investment in mastitis detection sensor systems, for farms with an automatic milking system (AMS) before and after the investment in mastitis detection sensor systems, and for farms with a conventional milking system (CMS) before and after the investment in mastitis detection sensor systems (analysis 1). Values represent model predictions and bars represent SE.

had a higher SCC in the years following investment in an AMS (Figure 1). Because all AMS farms have mastitis detection sensor systems, the results of our study can be directly compared with earlier studies on the effect of the introduction of an AMS on SCC. Many aspects change when farms start milking with an AMS - one such change is that farmers are no longer present during milking and have to use mastitis detection sensor systems to detect clinical mastitis. These detection models are not perfect (e.g., Kamphuis et al., 2010; Rutten et al., 2013), and it has been reported that $75 \%$ of clinical mastitis cases are missed when milking with an AMS (Hogeveen et al., 2013). It is interesting to note that CMS farms with mastitis detection sensor systems had a lower SCC after sensor investment. When using mastitis detection sensors in a CMS, the farmer is present and can immediately check any cows that generate a sensor alert. Moreover, cows that do not generate an alert but that have mastitis can be identified because the farmer still can visually inspect the cows before milking. In addition, on CMS farms, the investment in mastitis detection sensor systems is made deliberately and therefore farmers are more likely to use it intensively (Steeneveld and Hogeveen, 2015), resulting in greater attention to mastitis detection and, therefore, a lower average SCC.

Our results show that milk production increased in the years after investment in sensor systems on AMS

Table 3. Coefficient estimates ( $\beta$ ) of the mixed model for SCC (analysis 1) and milk production (analysis 2 ) for farms without sensor systems for mastitis detection and farms with sensor systems for mastitis detection in an automatic milking system (AMS) and in a conventional milking system (CMS)

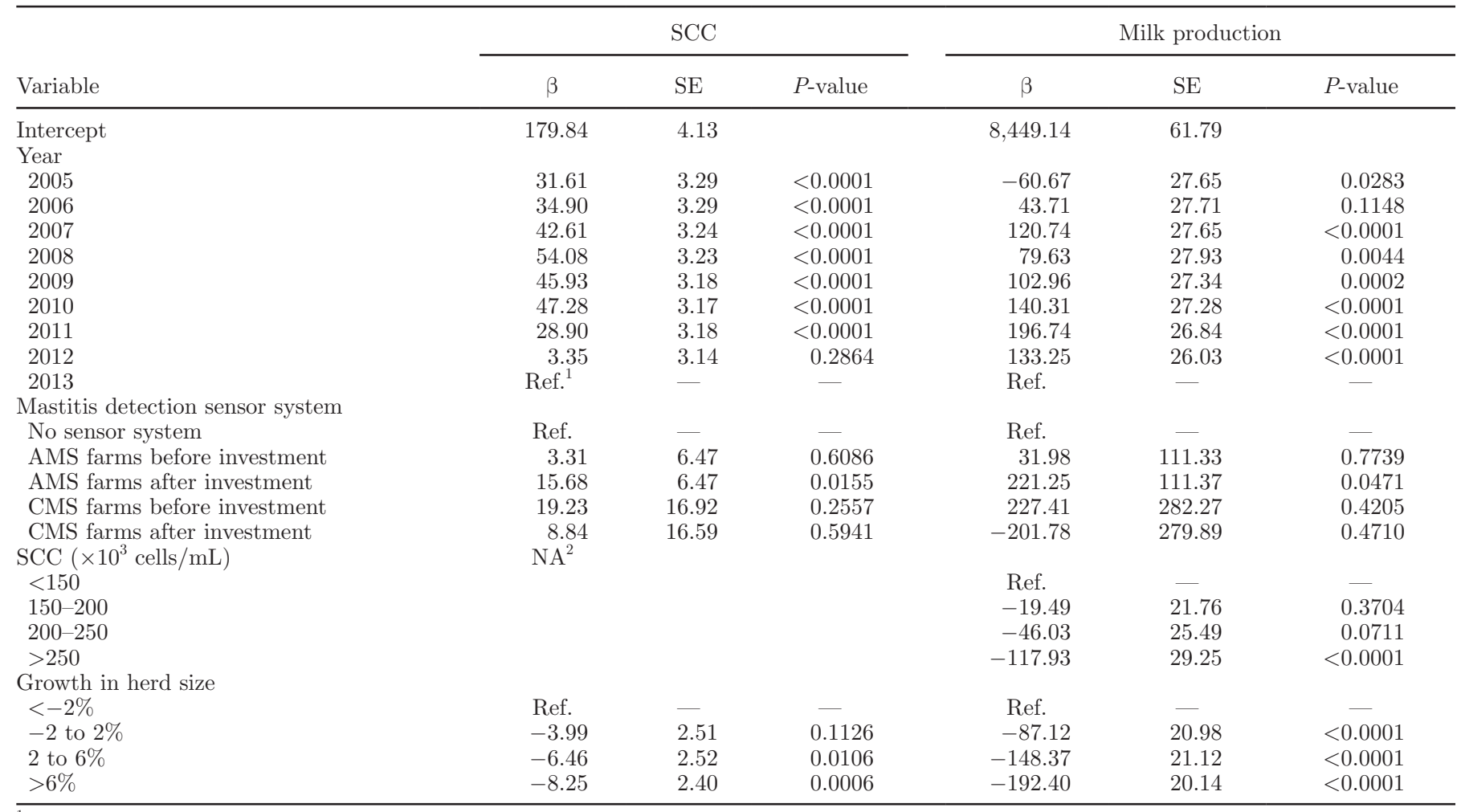

${ }^{1}$ Reference group.

${ }^{2}$ Not applicable. 


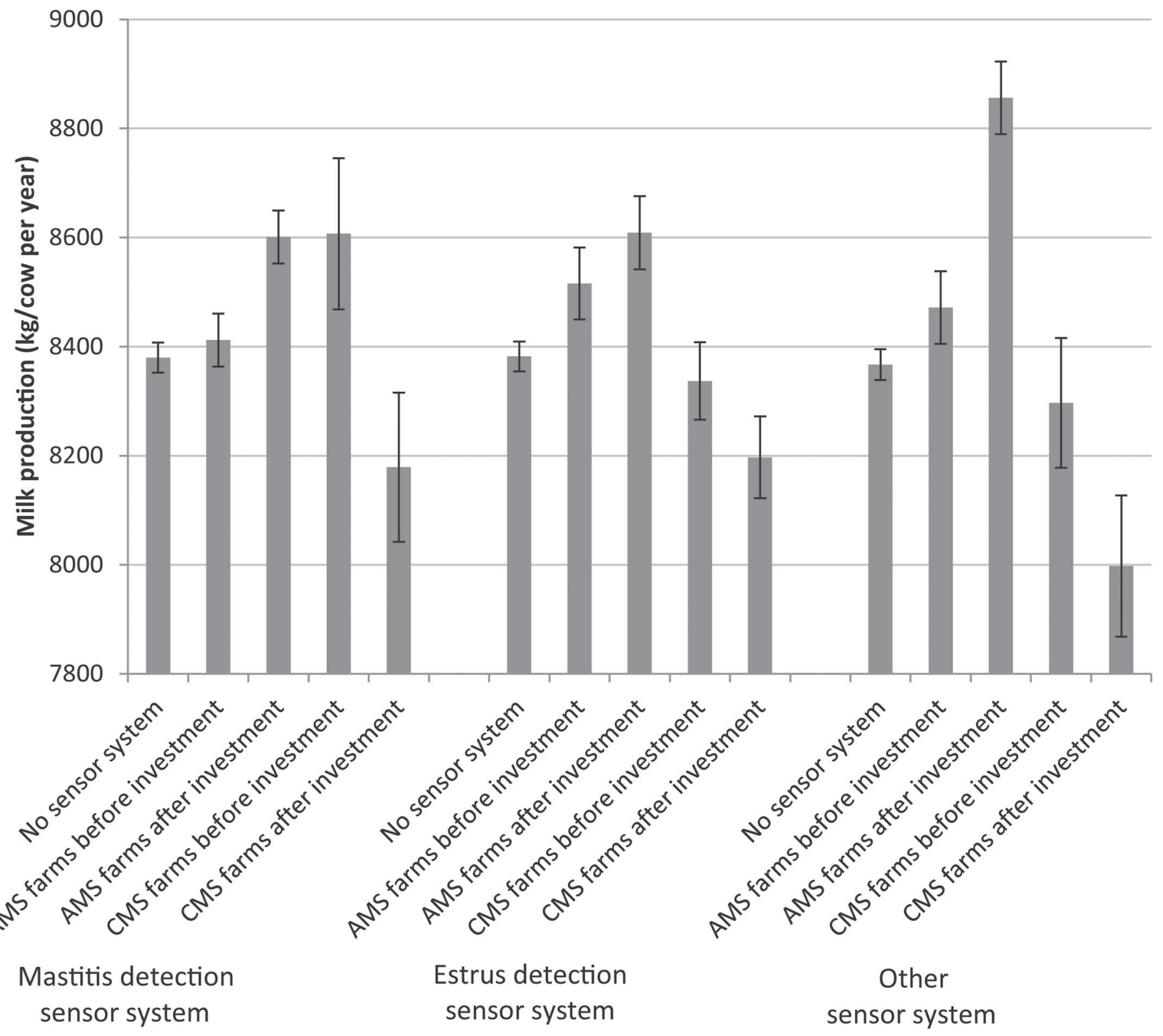

Figure 2. Estimated average yearly milk production per cow for farms with no investment in sensor systems, for farms with an automatic milking system (AMS), and for farms with a conventional milking system (CMS) before and after the investment in sensor systems (analyses 2, 4 , and 5). Values represent model predictions and bars represent SE.

farms (Figure 2). These results are consistent with previous research that found that milk production increased with an AMS, with the increase being due to the higher milking frequency (Kruip et al., 2002; Wagner-Storch and Palmer, 2003; Speroni et al., 2006). It was hard to determine, therefore, whether the increased milk production was caused by the increased milking frequency or by the use of sensor systems. The CMS farms with sensor systems had lower milk production in the years after investment in sensor systems (Figure 2). We did not expect that CMS farms with sensor systems would have lower milk production in the years after investment. This finding is likely explained by the fact that $96 \%$ of farmers with sensor systems and a CMS indicated that the investment in sensor systems was concurrent with another major change at the farm, such as a new barn or new milking system (Steeneveld and Hogeveen, 2015). Most likely, these changes led to a decrease in milk production that could not be compensated for by the use of sensor systems. Because almost all farmers reported a major change on the farm in the year of investment in sensor systems, we 
Table 4. Coefficient estimates ( $\beta$ ) of the mixed model for calving interval (analysis 3 ) and milk production (analysis 4) for farms without sensor systems for estrus detection and farms with sensor systems for estrus detection in an automatic milking system (AMS) and in a conventional milking system (CMS)

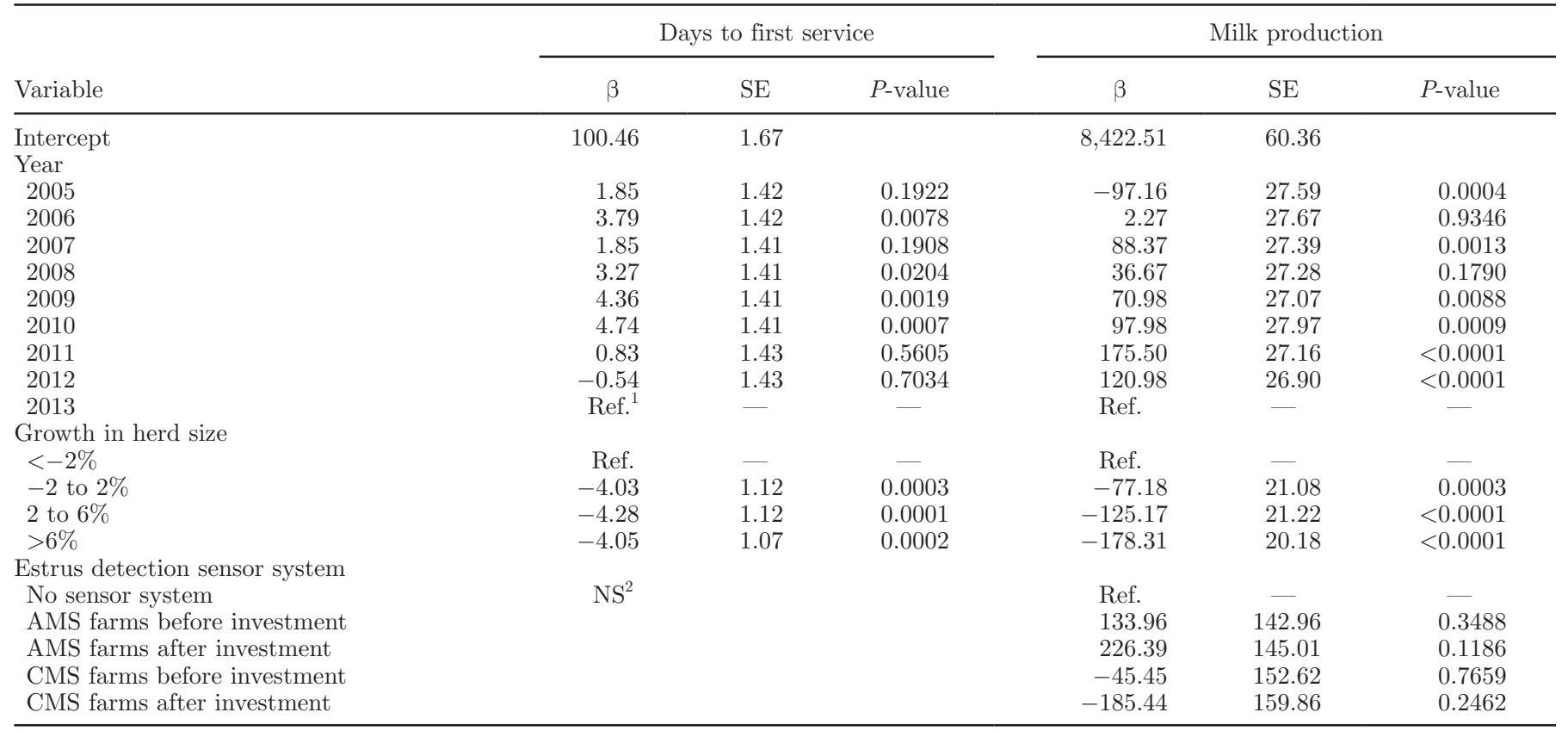

${ }^{1}$ Reference group.

${ }^{2}$ Not significant.

Table 5. Coefficient estimates ( $\beta$ ) of the mixed model for first calving age (analysis 5) and milk production (analysis 6 ) for farms with and without sensor systems for estrus detection for youngstock for farms without other sensor systems and farms with other sensor systems on an automatic milking system (AMS) and on a conventional milking system (CMS)

\begin{tabular}{|c|c|c|c|c|c|c|}
\hline \multirow[b]{2}{*}{ Variable } & \multicolumn{3}{|c|}{ First calving age } & \multicolumn{3}{|c|}{ Milk production } \\
\hline & $\beta$ & $\mathrm{SE}$ & $P$-value & $\beta$ & $\mathrm{SE}$ & $P$-value \\
\hline $\begin{array}{l}\text { Year } \\
2003\end{array}$ & 11.86 & 1.99 & $<0.0001$ & & \multicolumn{2}{|c|}{ Year } \\
\hline 2004 & 13.77 & 1.98 & $<0.0001$ & & & \\
\hline 2005 & 9.36 & 1.99 & $<0.0001$ & -81.83 & 27.74 & 0.0032 \\
\hline 2008 & 6.61 & 1.97 & 0.0008 & 61.07 & 27.39 & 0.0258 \\
\hline 2009 & 8.58 & 1.97 & $<0.0001$ & 99.52 & 27.21 & 0.0003 \\
\hline 2010 & 6.85 & 1.97 & 0.0005 & 127.55 & 26.99 & $<0.0001$ \\
\hline 2011 & 8.41 & 1.97 & $<0.0001$ & 185.61 & 27.21 & $<0.0001$ \\
\hline 2012 & 3.49 & 1.97 & 0.0773 & 137.95 & 26.90 & $<0.0001$ \\
\hline 2013 & Ref. ${ }^{1}$ & - & - & Ref. & - & - \\
\hline \multicolumn{7}{|l|}{ Sensor system } \\
\hline \multicolumn{7}{|l|}{ Growth in herd size } \\
\hline$<-2 \%$ & & & & Ref. & - & - \\
\hline-2 to $2 \%$ & & & & -77.48 & 21.27 & 0.0003 \\
\hline 2 to $6 \%$ & & & & -120.53 & 21.45 & $<0.0001$ \\
\hline$>6 \%$ & & & & -169.59 & 20.46 & $<0.0001$ \\
\hline
\end{tabular}

${ }^{1}$ Reference group.

${ }^{2}$ Not applicable. 
were unable to separate the effect of the sensor system and the effect of the other major change. Rutten et al. (2014) developed a computer simulation model and reported a positive effect of activity meters on milk production and reproduction. Our results in the current study from commercial dairy farms show, however, that these effects were not present. In fact, for farms with sensor systems, an opposite effect (i.e., lower milk production) was observed in our study. This might be caused by circumstances on commercial dairy farms (e.g., new milking system, new barn, and growth in herd size) that were not taken into account in the normative study of Rutten et al. (2014). Growth in herd size was corrected for in the current study, and results showed that growth in herd size negatively affected milk production per cow per year (Tables 3 , 4, and 5).

Having estrus detection sensor systems did not affect age at first calving or days to first service. It is frequently reported that use of estrus detection sensor systems results in improved estrus detection (e.g., Hockey et al., 2010; Kamphuis et al., 2012) but our results showed that heifers and dairy cows were not inseminated earlier on farms with estrus detection sensors. It is possible that farmers detect estrus better with the sensor system but still use the same rules on when to start inseminating, resulting in no change in age at first calving or days to first service. For instance, regardless of sensor use, farmers might inseminate heifers from a certain BW or age onward or after a voluntary waiting period. Age at first calving is mostly influenced by the farmer choosing the time to start inseminating (Mohd Nor et al., 2013). A more likely reason for a lack of effect might be found in the motivation to invest. Most farmers invested in estrus detection sensor systems to improve the estrus detection rate and reduce labor (Steeneveld and Hogeveen, 2015). Thus, farmers invest in sensor systems to ease management on their farms with less focus on improving measures of health and production of the herd. Another reason for not finding an effect on age at first calving and days to first service could be that most investments in estrus detection sensor systems occurred in recent years (Steeneveld and Hogeveen, 2015).

For analyses on reproduction, days to first service and age at first calving were the dependent variables. In the provided data set, other reproduction parameters were available, such as the number of inseminations per cow and nonreturn rate. We decided not to use these parameters because CRV indicated that they are less reliable (as re-inseminations are not always recorded). For mastitis detection, more information about the udder health status of the farms was available (percentage of cows with high SCC and percentage of cows with new high SCC); however, using this information gave the same insights as the analyses on average SCC (results not shown).

The farms were not randomly selected in the Netherlands, and some selection bias could have occurred. All farms were connected to the farm accounting agency, and all farmers voluntarily completed the survey and gave CRV permission to use data on measures of health and production. Annual economic reports are generally of interest to farmers who have a special interest in their financial performance. The farmers in our data set could be characterized as farmers who were interested in getting information about their financial performance to assist in making better management decisions. Therefore, it is not unexpected that the overall herd size (101 cows) was higher than the current Dutch average of 91 cows (LEI, 2013). There was, however, a significant difference in herd size between farms with and without sensor systems. In 2013, farms without any sensor system had an average herd size of 94 cows, whereas AMS and CMS farms with sensor systems had herds of 103 and 128 cows, respectively (data not shown). Most likely, farms with sensor systems are more future-oriented and are therefore larger those without sensor systems. From Table 2, it can be seen that farms grew (in herd size) after sensor investment, and the CMS farms grew at a faster rate than the AMS farms. This is likely because the CMS farms had fewer limitations on growth than AMS farms because the milking parlor has no capacity limitations or because a CMS is deliberately chosen by farmers who want to grow further. Overall, milk production level $(8,330 \mathrm{~kg} / \mathrm{cow}$ per year), calving interval $(415 \mathrm{~d})$, and age at first calving (783 d) in 2013 were comparable with the Dutch averages for the same year (CRV, 2013), whereas the SCC $(177,000$ cells $/ \mathrm{mL})$ was lower than the Dutch average (199,000 cells/mL; PZ, 2012).

Sensor systems did not have positive effects on days to first service, age at first calving, or milk production. For most farms, however, the reasons for investing in sensor systems were related to reducing labor and easing herd management (Steeneveld and Hogeveen, 2015). This means that using sensor systems can have a positive economic effect on the farm, especially due to the reduced labor costs. Further investigations must focus on whether a substitution of capital for labor occurs on farms that invest in sensor systems, and whether farms differ in their capital:labor ratio before and after investment in sensor systems.

\section{CONCLUSIONS}

Having a mastitis detection sensor system was associated with a decreased average SCC on CMS farms and with an increased average SCC on AMS farms in the 
years after sensor investment. Having sensor systems was associated with a higher average production per cow on AMS farms, and with a lower average production per cow on CMS farms in the years after investment. Use of an estrus detection sensor system did not improve reproduction performance. Labor reduction was an important reason for investing in sensor systems. Therefore, economic benefits from investments in sensor systems can be expected more because of the reduction in labor costs than from improvements in measures of health and production of the herd.

\section{ACKNOWLEDGMENTS}

The authors thank the dairy farmers for completing the survey, and Accon AVM (Leeuwarden, the Netherlands) and CRV (Arnhem, the Netherlands) for providing data about the farms. This research was supported by NWO (Netherlands Organisation for Scientific Research, The Hague, the Netherlands).

\section{REFERENCES}

Auldist, M. J., G. O'Brien, D. Cole, K. L. Macmillan, and C. Grainger. 2007. Effects of varying lactation length on milk production capacity of cows in pasture-based dairying systems. J. Dairy Sci. 90:3234-3241.

Büchel, S., and A. Sundrum. 2014. Short communication: Decrease in rumination time as an indicator of the onset of calving. J. Dairy Sci. 97:3120-3127.

Chapinal, N., A. M. de Passillé, J. Rushen, and S. Wagner. 2010. Automated methods for detecting lameness and measuring analgesia in dairy cattle. J. Dairy Sci. 93:2007-2013.

CRV. 2013. Annual report 2013. CRV, Arnhem, the Netherlands.

Dohmen, W., F. Neijenhuis, and H. Hogeveen. 2010. Relationship between udder health and hygiene on farms with an automatic milking system. J. Dairy Sci. 93:4019-4033.

Dohoo, I. R., S. W. Martin, and H. Stryhn. 2009. Veterinary Epidemiological Research. Atlantic Veterinary College Inc., Charlottetown, Prince Edward Island, Canada.

Firk, R., E. Stamer, W. Junge, and J. Krieter. 2002. Automation of oestrus detection in dairy cows: A review. Livest. Prod. Sci. 75:219-232.

Halasa, T., M. Nielen, A. P. W. De Roos, R. Van Hoorne, G. de Jong, T. J. G. M. Lam, T. van Werven, and H. Hogeveen. 2009. Production loss due to new subclinical mastitis in Dutch dairy cows estimated with a test-day model. J. Dairy Sci. 92:599-606.

Hockey, C. D., J. M. Morton, S. T. Norman, and M. R. McGowan. 2010. Evaluation of a neck mounted 2-hourly activity meter system for detecting cows about to ovulate in two paddock-based Australian dairy herds. Reprod. Domest. Anim. 45:e107-e117.

Hogeveen, H., K. J. Buma, and R. Jorritsma. 2013. Pages 313-319 in Precision Livestock Farming '13, Leuven, Belgium. D. Berckmans and J. Vandermeulen, ed.
Holman, A., J. Thompson, J. E. Routly, J. Cameron, D. N. Jones, D. Grove-White, R. F. Smith, and H. Dobson. 2011. Comparison of oestrus detection methods in dairy cattle. Vet. Rec. 169:47.

Inchaisri, C., R. Jorritsma, P. Vos, G. C. van der Weijden, and H. Hogeveen. 2010. Economic consequences of reproductive performance in dairy cattle. Theriogenology 74:835-846.

Kamphuis, C., B. DelaRue, C. R. Burke, and J. Jago. 2012. Field evaluation of 2 collar-mounted activity meters for detecting cows in estrus on a large pasture-grazed dairy farm. J. Dairy Sci. 95:3045-3056.

Kamphuis, C., H. Mollenhorst, J. A. P. Heesterbeek, and H. Hogeveen. 2010. Detection of clinical mastitis with sensor data from automatic milking systems is improved by using decision-tree induction. J. Dairy Sci. 93:3616-3627.

Kruip, T. A. M., H. Morice, M. Robert, and W. Ouweltjes. 2002. Robotic milking and its effect on fertility and cell counts. J. Dairy Sci. 85:2576-2581.

LEI. 2013. Agricultural Economics Research Institute. Agricultural statistics. Accessed Nov. 1, 2014. http://www3.lei.wur.nl/BIN_ ASP $/$ show.exe aktie $=$ vindtoon $\& b j=2010 \& e j=2013 \&$ language $=\mathrm{N}$ L\&Valuta $=2 \&$ publicatieID $=3 \&$ kiestabel $=2.02 \&$ Database $=$ LTC.

Miekley, B., I. Traulsen, and J. Krieter. 2012. Detection of mastitis and lameness in dairy cows using wavelet analysis. Livest. Sci. 148:227-236.

Mohd Nor, N., W. Steeneveld, T. van Werven, M. C. M. Mourits, and H. Hogeveen. 2013. First-calving age and first-lactation milk production on Dutch dairy farms. J. Dairy Sci. 96:981-992.

O’Connell, J., F. A. Tøgersen, N. C. Friggens, P. Løvendahl, and S. Højsgaard. 2010. Combining cattle activity and progesterone measurements using hidden semi-Markov models. J. Agric. Biol. Environ. Stat. 16:1-16.

Pastell, M., J. Tiusanen, M. Hakojarvi, and L. Hanninen. 2009. A wireless accelerometer system with wavelet analysis for assessing lameness in cattle. Biosystems Eng. 104:545-551.

PZ. 2012. Dairy farming. Accessed October 20, 2014. http://www prodzuivel.nl/pz/productschap/publicaties/zic/zicmvh2012.pdf.

Rasmussen, M. D., M. Bjerring, P. Justesen, and L. Jepsen. 2002. Milk quality on Danish farms with automatic milking systems. J. Dairy Sci. 85:2869-2878.

Rutten, C. J., W. Steeneveld, C. Inchaisri, and H. Hogeveen. 2014. An ex ante analysis on the use of activity meters for automated estrus detection: To invest or not to invest? J. Dairy Sci. 97:6869-6887.

Rutten, C. J., A. G. J. Velthuis, W. Steeneveld, and H. Hogeveen. 2013. Invited review: Sensors to support health management on dairy farms. J. Dairy Sci. 96:1928-1952.

Speroni, M., G. Pirlo, and S. Lolli. 2006. Effect of automatic milking systems on milk yield in a hot environment. J. Dairy Sci. 89:4687-4693.

Steeneveld, W., and H. Hogeveen. 2015. Characterization of Dutch dairy farms using sensor systems for cow management. J. Dairy Sci. 98:709-717.

van der Tol, R., and A. van der Kamp. 2010. Time series analysis of live weight as health indicator. Pages 230-231 in Proc. First North Am. Conf. Precision Dairy Management, Toronto, Canada.

Wagner-Storch, A. M., and R. W. Palmer. 2003. Feeding behavior, milking behavior, and milk yields of cows milked in a parlor versus an automatic milking system. J. Dairy Sci. 86:1494-1502. 